\title{
An Appraisal of the Factors Influencing Rural-Urban Migration in Some Selected Local Government Areas of Lagos State Nigeria
}

\author{
AWOREMI, JOSHUA REMI, $P h D$ \\ DEPARTMENT OF MANAGEMENT SCIENCE \\ LADOKE AKINTOLA UNIVERSITY OF TECHNOLOGY \\ P.M.B. 4000, OGBOMOSO, NIGERIA \\ Tel: 234-80-3396-7307 E-mail: aworemi_remi@yahoo.com
}

ABDUL-AZEEZ, IBRAHEEM ADEGOKE

DEPARTMENT OF BUSINESS ADMINISTRATION AND MANAGEMENT TECHNOLOGY

LAGOS STATE UNIVERSITY, P.M.B. 0001, LASU POST OFFICE OJO, LAGOS, NIGERIA

Tel: 234-70-3655-5582 E-mail: ibforson@yahoo.com

OPOOLA, NURAIN. A.

DEPARTMENT OF MANAGEMENT SCIENCE

LADOKE AKINTOLA UNIVERSITY OF TECHNOLOGY

P.M.B. 4000, OGBOMOSO, NIGERIA

Tel: 234-80-5520-9190Ｅ-mail: nurainopoola@yahoo.com

Received: February 22, 2011

Accepted: May 5, 2011

doi:10.5539/jsd.v4n3p136

\begin{abstract}
This study identifies the factors influencing the rural-urban migration in some selected local government areas of Lagos State. It was carried out in Lagos because of its high concentration of migrants from different parts of the world. About 15 of the 20 Local Government Areas (LGAs) in the State make up Lagos metropolis. These 15 LGAs were purposively chosen based on perceived migrants population and six (6) of these were randomly selected within their categories. In each LGA, the street listings of the 1991 National Census were used to draw a random list of seven streets from which 10 respondents were selected. Only 400 interview guides were however analyzed given the dearth of relevant data from the remaining 20.

Data were collected by the use of pre-tested interview guide to elicit information from the respondents in the study areas. Logistic regression model was adopted for the data analysis.

The study revealed that unemployment, education, family reasons, inadequate social amenities in the rural communities, avoidance of boredom in agriculture and health reasons are the major factors influencing rural-urban migration in Nigeria. It was however recommended that to stem down the rate of the migration, functional amenities such as pipe borne water, electricity, recreational facilities should be provided in the rural areas. Good educational facilities and qualified teachers should be made available in the rural areas. Agro-allied industries must be set-up in the rural areas in order to provide job opportunity for the rural dwellers.
\end{abstract}

Keywords: Factors, Migration, Migrants, Rural, Urban

\section{Introduction}

In many developing nations, there had been a rapid growth of urban population far more than that of rural population. Nigeria is a typical example of this, where there had been a tremendous expansion of urban areas consequent to the rapid rural urban migration. In 1974 rural population was $75 \%$ of the total population but by 2001 urban population had assumed a high dimension of $44 \%$ of the country's population. This rapid urban growth portends serious implications on the environmental and the well being of the citizenry. 
In Africa, estimates have shown that between 1990 and 2020, half a billion people will be added to already overcrowded conurbations as against the less than 200 million people in north America and Europe (USAID, 2002). Such rapid urban growth in these African countries including Nigeria started even before independence. The migration far outstrips services and infrastructural deployment resulting in deepening crisis in basic municipal services, a situation which was later further worsened by the Structural Adjustment Programme of the 1980s to which Nigeria has hardly recovered from. Also in Nigeria, the rural populace move out in large numbers temporarily or permanently to towns and cities to seek out new opportunities, improved livelihoods and better standard of living. Subsequently, however, they end up in city slums scratching out a living with limited capacity to adapt to socioeconomic changes in the new environments they find themselves. Predominantly, their livelihood patterns contribute significantly to climate change and the negative impacts of this change.

According to Braunvan, (2004) people tend to be pulled to the areas of prosperity and pushed from areas of decline. Migrants are usually concerned with the benefits they hope to gain by moving and usually give less thought to the problems that they will incur as a result of the process. Some of these problems may impact more on the non-migrants left behind in the rural area. The movement of people from rural to urban areas is a common occurrence in Nigeria. The

movement poses some problems in the rural as well as in the urban center even though, there are benefits derived from it. In most rural areas, the impact of rural-urban migration was a rapid deterioration of the rural economy leading to chronic poverty and food insecurity (Mini, 2000). This arises mainly due to excessive drain of youth from the rural populace thus leaving only the

older and aged members to constitute the labour force of the rural area.

This study was therefore designed to appraise the reasons for rural-urban migration in some selected local government areas in Lagos state. Specifically, the study attempted to:

i. Identify the reasons and examine the various factors affecting rural-urban migration in the rural areas.

ii. Examine the problems of rural-urban migration in Nigeria.

iii. Identify the benefits of rural-urban migration.

\section{Rural-urban migration in Nigeria}

The burden of rural-urban migration in Nigeria is multifaceted and intertwining. As such, an analysis of one decomposable component or consequence, such as unbearable population density, impinges on other issues within the identifiable cycle of burdens. For instance, in examining the immediate effect of rural to urban migration, which is increase in population or at the extreme its explosion, various other subsequent effects are expected to be considered. Population explosion activates the housing challenge both at micro family and macro society levels. Congestion in households and communities has implications for both the health and psychology of victims. Nigerian cities such as Lagos, Port-Harcourt, Kano, Onitsha among others are characterized by human traffic, vehicular congestions, environmental pollution, consistent in-migration and spurious expansion of territories to accommodate human additions.

Lagos is the mostly affected city in term of unplanned growth, around $85 \%$ of the country's industrial activity is located in Lagos and it is one of the fastest growing cities in the world. Its annual growth rate was estimated at almost $14 \%$ during the 1970s and its current population is estimated to be 15 million (Census, 2006). Projections suggest that by 2020 it will be the third biggest in the world (USAID, 2002). Rural-urban migration has a significant impact on unemployment levels of the destination cities. Between 1998 and 1999, urban unemployment rose from $5.5 \%$ to $6.5 \%$, a rate higher than the national unemployment which increased from $3.9 \%$ to $4.7 \%$ during the same period (USAID, 2002)

Unplanned population increases in most cities explain infrastructural decay in relevant contexts. This is especially the case in Nigeria where maintenance of existing amenities, which ab-initio are haphazardly situated due to unprecedented corruption and biased award of contracts, is not prioritized (Okafor, 2005). It is interesting to note that most roads in the country are impassable, hospitals lack human and necessary material resource, schools are dilapidated and electricity supply is very far from stable - in most rural communities though, none of these infrastructures exists. The people's agony is visible in frustrations arising from avoidable diseases and deaths, lack of access to portable water, subsistent economic activities, various kinds of unemployment, child abuse in all its ramifications and dwindling focus on societal norms and values (Nwokocha, 2007).

Rural communities share this burden through loss of manpower necessary for agricultural activities and production. The impoverishment of rural areas in Nigeria is partly explainable by out-migration of able youths in 
search of employment in cities. Consequently, agriculture which prior to discovery of oil was the mainstay of Nigeria's economy was far relegated to the background leading to the country's mono-economy status. Overdependence on oil, it is argued here, has led to employment crisis and avoidable importation of agricultural products, which together have over the years had negative net effect on local industries and productions as well as international trade balances. Several analyses of Nigeria's economy insist that petroleum resources have been more of a curse rather than a blessing to the development of the country (Iwayemi, 2006)

It is imperative to note that some migrants in the category discussed in the present paper overcame their locality-imposed powerlessness in new destinations, while a large majority of others became more impoverished to the point of becoming social misfits otherwise known as "area boys and girls". Another burden imposed by rural to urban migration is the increasing number of cohabitation and consensual unions that results among the married and the not yet married. Although it could be argued in some quarters that such union, especially when it involves people from different ethnic backgrounds, could have positive implications for the country's unity at macro level, the negative consequences on existing marriages and family unity at the micro are enormous. The above issues constitute the burden and in some cases agony of rural-urban migration in Nigeria for which organized critical thinking and context specific intervention strategies are essential.

\section{Rural-Urban Migration Theory}

Rural to urban migration has historically been an important part of the urbanization process and continues to be significant in scale in developing countries. Internal migration accounted for at least half of all urban growth in Africa during the 1960s and 1970s and about 25\% of urban growth in Africa in the 1980s and 1990s (Brockerhoff, 1995). In Brazil, it is estimated that over 20 million people moved from rural to urban areas between 1950s and the 1970s. Similarly, around 21 million people in India (30\% of the national urban growth) moved from rural to urban areas in 1990s (Census of India, 2005).

The decision to migrate involves 'push factors' which force migrant out of the rural areas as well as 'pull factors' which attracts migrants to urban areas. The earlier model developed by Harris and Todaro (1976) explains rural-urban migration as a response to the expected rather than current income differential between rural and urban areas. In other words, workers will continue to migrate from rural to urban areas until wages they expect to earn in urban areas are equal to the wages they expect to earn in the rural areas. Numerous empirical research have built on this foundation to examine individuals' motivation to migrate from rural to urban areas and majority reveal that the primary motivation is indeed economic considerations (Connell et al 1977, Baril et al 1986).

Some studies indicate that economic push factors (for example lack of rural credit, unemployment, lack of land, general rural poverty) are most important while others suggest that economic pull factors (e.g. perception of high wages from urban employment) are predominant. A number of other motivations for rural-urban migration including educational opportunities offered in urban areas, marriage and joining the family already at the destination are cited in the literature. Also, a few studies suggest that rural-urban migration is facilitated by the concentration of migrants of same origin in the destination city (Mora \& Taylor, 2005).

Migrants often have a difficult time finding jobs in cities as they are more likely to have only imperfect information about the type or quality of job opportunities they face (Banerjee, 1984). To find a job, they usually go through friends, family and other informal networks (Banerjee and Bruce, 1995). In addition, Yamauchi and Tanabe (2003) argue that finding a job is often facilitated if there is a large network of people from the same origin as the migrant at the destination but this could also reduce the probability of finding a job if these migrants have to compete for the same jobs. It is also important to understand how rural-urban migration evolves over the development process but the available research is limited and inconclusive. The UN (1980) estimates a significant positive relationship between rural-urban out migration rates and the standard of living of citizens. On the other hand, Ledent (1982) concludes that the evolution of rural-urban migration rate and standard of living follows the following pattern "it first increases, reaches a maximum and then decreases towards a value of zero".

The existing research on the impact of rural-urban migration on development in Nigeria is also limited and inconclusive. Fadayomi (1998) reveals that internal migration has a negative impact on the quality of rural life because it reduces the number of individuals in rural areas. Migration of young adults from the rural areas places a greater burden on the remaining farmers as they now have to work harder and longer to cover the same area of land thus depriving them of some of their leisure time. On the other hand, Ijere (1994) reveals that rural-urban migration has a positive impact on urban growth and social development and this helps generate employment, educational facilities and transportation infrastructure for the migrants. However, this argument is questionable 
when one considers the fact that it has been shown that urban areas in Nigeria are plagued with social problems, unemployment, poverty and deficit of infrastructure.

\section{Factors Affecting Rural-Urban Migration}

Three categories of factors are perceived as important reasons for rural-urban migration. The first set is related to the need for education and acquisition of skills in various vocations. The second set relate to the absence of desirable job opportunities in rural areas. These include the absence of employment, absence of industries and companies and boredom in agriculture. The third set of factors is social, such as inadequate amenities and expulsion from rural areas due to an offence or crime committed by the migrant. The first two sets of factors are common in rural-urban migration literature as factors responsible for the movement of migrants. Of the social factors are, however, only inadequate social amenities has a fair mention in the literature (Mabawonku,1973; Sabot, 1972).

\section{Methodology}

The study was carried out in Lagos because of its high concentration of migrants from different parts of the country. Lagos is the commercial nerve centre of Nigeria with an estimated population of about 12 million. About 15 of the 20 Local Government Areas (LGAs) in the State make up Lagos metropolis. These 15 LGAs were purposively categorized based on perceived migrants population and six (6) of these were randomly selected within their categories. The six LGAs represented low migrants population (i.e. Eti-Osa and Ikoyi LGAs), medium migrants population (i.e. Kosofe and Surulere LGAs) and high migrants population (i.e. Ajeromi/Ifelodun and Agege LGAs) sectors of the city. In each LGA, the street listings of the 1991 National Census were used to draw a random list of seven streets from which 10 respondents were selected. Only 400 interview guides were however analyzed given the dearth of relevant data from the remaining 20.

Data were collected by the use of pre-tested interview guide to elicit information from the respondents in the study areas. Logistic regression model was adopted for the data analysis. Among the variables identified to be influencing rural-urban migration are; unemployment, education, family reasons, inadequate social amenities, avoidance of boredom in agriculture and health reasons. The Logistics regression is mathematically represented as;

$\mathrm{Y}=\mathrm{f}\left(\mathrm{X}_{1}, \mathrm{X}_{2}, \mathrm{X}_{3}, \mathrm{X}_{4}, \mathrm{X}_{\mathrm{n}} \ldots \ldots \ldots \ldots \ldots \mathrm{U}_{\mathrm{n}}\right)$

$\mathrm{Y}=$ Rural-urban migration

$\mathrm{X}_{1}=$ Education

$\mathrm{X}_{2}=$ Unemployment

$\mathrm{X}_{3}=$ Health

$\mathrm{X}_{4=}$ Boredom in Agriculture

$\mathrm{X}_{5}=$ Inadequate social amenities

$\mathrm{X}_{6}=$ Family reasons

The logistic regression model is employed to analyze the binary data that the Linear Multiple Regression model failed to analyze effectively within the range of rural-urban migration. Unlike Linear Multiple Regression model, the Logistic model forces the estimated probabilities to lie within the range of 0-1 (Bryan, 1994).

This implies that

$$
\log \left(\mathrm{P} / 1-\mathrm{P}_{1}\right)=\beta_{0}+\beta_{1} \mathrm{Y}_{1}+\beta_{2} \mathrm{Y}_{2}+\ldots \ldots \ldots \ldots+\beta_{\mathrm{k}} \mathrm{Y}_{\mathrm{k}}
$$

If

$$
\begin{gathered}
P_{1}=e^{\beta 0+\beta 1 Y 1+\beta 2 Y 2+\ldots . .+\beta k Y k} \\
1+e^{\beta 0+\beta 1 Y 1+\beta 2 Y 2+\ldots . .+\beta k Y k}
\end{gathered}
$$

Then

$$
\lambda_{1}=\beta_{0}+\beta_{1} \mathrm{Y}_{1}+\beta_{2} \mathrm{Y}_{2}+\ldots \ldots \ldots \ldots+\beta_{\mathrm{k}} \mathrm{Y}_{\mathrm{k}}
$$

$$
\mathrm{P}_{1}=\mathrm{e}^{\lambda} / 1+\mathrm{e}^{\lambda}
$$

When a Linear Logistic model fitted to explore the relationship between a Bernolli response variable and one of more independent variables, the model is referred to as Logistic Regression model (Agrersti, 1990).

\section{Results and Discussion}

In this study, the Logistic regression was used to fit a model in the exploration of the relationship between the dependent variable of rural-urban migration $(\mathrm{Y})$ and the independent variables of Education $\left(\mathrm{X}_{1}\right)$, Unemployment $\left(\mathrm{X}_{2}\right)$, Health $\left(\mathrm{X}_{3}\right)$, Boredom in Agriculture $\left(\mathrm{X}_{4}\right)$, Inadequate social amenities $\left(\mathrm{X}_{5}\right)$, and Family reasons $\left(\mathrm{X}_{6}\right)$

Table 1 shows that the coefficient $(\beta=1.6014)$ of $X_{1}$ implies that when the independent variable, Education changes by 1 unit and the values of other independent variables remain constant, the logarithm of odds of rural-urban will increase by 1.6014 . This means that as the need for education increases, there would be increase 
in the rate at which people migrate from rural to urban areas. This is because there is believe that schools in urban areas are better equipped and exposed to many facilities and amenities than schools in rural areas. This is significant at $10 \%$.

The coefficient $(\beta=8.1744)$ of $\mathrm{X}_{2}$ shows that unemployment is of vital contributory factor to rural-urban migration. This is due to the absence of companies, and other institutions that can employ people in the rural areas, therefore people move to urban cities for the proverbial greener pasture. This migration in turn has a significant impact on unemployment levels of the destination cities. For example between 1998 and 1999, urban unemployment rose from $5.5 \%$ to $6.5 \%$, a rate higher than the national unemployment which increased from $3.9 \%$ to $4.7 \%$ during the same period (USAID, 2002). This value is also significant at $5 \%$ level, which implies that unemployment had contributed significantly to the rural-urban migration in the study area.

Health reasons are also among the factors influencing rural-urban migration in the study area. The coefficient of $X_{3}(\beta=0.3835)$ showed that when the independent variable, health changes by 1 unit and the value of other independent variables remain constant, logarithm of the odds of rural-urban migration increases by 0.3835 unit. This means that as the need for quality health care increases in the rural areas there is every tendency for rural-urban migration to also increase. In nutshell, rural areas are believed to lack quality health care services, such as well equipped hospital, good laboratory services and other health care services.

Avoidance of boredom in Agriculture has contributed largely to rural-urban migration. The coefficient ( $\beta=$ 4.3015) of the variable $X_{4}$ showed that when the variable changes by 1 unit and the other variables remain constant, the logarithm odds of rural-urban migration increases by 4.3015 units. Adults are the most influenced by this factor, because they believed that moving to cities will earn them quick money with less stress. Unlike agriculture, especially the crude method which requires much energy but less output. This kind of migration leaves older farmers to continue cultivating in their old method and therefore leads to insufficient or low agricultural production.

Inadequate social amenities are also a vital factor affecting rural-urban migration. This has a coefficient of 10.5852 which happens to be the most influential factor in the study area. What this implies is that absence of pipe borne water, electricity, good shelter, recreational facilities and other amenities that are crucial to human existence resulted in en-mass movement of people from the rural areas to city centres.

Family reasons was also mentioned as one of the factors influencing rural-urban migration, though its impact is low $(\beta=0.1687)$, but still it is also considered as one of the influential factors in rural-urban migration. The reason is that when the family head decides to move, the rest of the family normally follows. This factor is also important because it may cover a lot of less desirable migration.

\section{Conclusion and Recommendations}

This study has shown that rural-urban migration is a double-edge problem affecting the rural community as well as the destination urban areas. The rural community is being affected in such a way that youths and adults that suppose to remain in the community and contribute their own quota to the development of agriculture and their community are no longer available in the rural areas. They move to urban centres in search for non-available greener pasture and abandon the farming activities which they believe cannot earn them what they will get in the urban areas. Subsequently this tends to reduce agricultural production and food availability in the country.

In urban areas, increase in the population of urban dwellers tends to lead to inadequate housing, poor education due to overcrowded schools, inadequate health care facilities, increase in criminal activities, traffic problems, few employment opportunities and other social problems which can make life difficult for the urban inhabitants.

Therefore, in other to curtail all of the stated problems, the study recommends that functional amenities such as pipe borne water, electricity, recreational facilities should be provided in the rural areas. Good educational facilities and qualified teachers should be made available in the rural areas. Agro-allied industries must be set-up in the rural areas in order to provide job opportunity for the people of the rural area and reduce rural-urban migration. Agricultural inputs and farming technology such as mechanization should be introduced to the rural people to improve the production. Good road should be constructed in the rural areas; also credit facilities should be made available with relaxed terms and condition.

In conclusion, if all the recommendations can be fully implemented it will greatly reduce the rural-urban migration in the country and also increase the food production capacity of the nation.

\section{References}

Banerjee B. (1984). Information flow, expectations and job search: Rural-to-Urban migration process in India. Journal of Development Economics. Vol. 15 pp. 239-257. 
Banerjee B. and Bucci, G. (1995). On the job search in a developing country: An Analysis based on Indian data on migrants. Economic Development and Cultural Change, Vol. 43 no 3 pp. 565-583.

Baril, R., Joel G., and Rulx-leonel J. (1986). Exodus as a strategy of survival: the case of rural Haiti, Environnement Caraibe, No 2, 69-104.

Braunvan, J. (2004). Towards a renewed focus on rural development, Agriculture and Rural Development 11(2) pp. 4-6.

Brocherhoff, M. (1995). Fertility and family planning in Africa cities; the impact of female migration, Journal of Biosocial Science, Vol. 27, 347-358.

Bryan, P. (1994). Econometric. Palgrave Publishers, pp. 98.

Connell, J., Dasgupta B., Laishly R., Lipton M. (1977). Migration from rural areas: evidence from village studies. Oxford University Press, New Delhi.

Fadayomi, T. O, Titilola, S. O., Oni, B and Fapohunda, O. J. (1992). Migration, Development and Urbanization Policies in Sub-Saharan Africa. CODESRIA, Darkar.

Ijere, N. J. (1994). Gender and rural-urban migration in the Ecuadorian sierra, Columbia University Press, Columbia.

Iwayemi, A. (2000). Nigeria's Oil Wealth: the Challenge of Sustainable Development in an Economy Dependent on Non-Renewable Natural Resources. University of Ibadan Postgraduate School 31st Interdisciplinary Research Discourse. Ibadan: University of Ibadan.

Ledent J. (1982). Rural-urban migration, urbanization, and economic development, Economic Development and Cultural Change, Vol. 30 no 3, 507-538.

Mabawonku, A.F. (1973). The impact of Rural-Urban Migration on the economy of selected rural communities in western Nigeria. Unpublished M.Sc. Thesis, Department of Agricultural Economics, University of Ibadan.

Mora J., and Taylor J. (2005). Determinants of migration, destination, and sector choice: disentangling individual, households, and community effects in international migration, remittances and the brain drain. Ozden and Schiff eds; the world Bank and Palgrave Macmillan, 21-51.

Nwokocha, E.E. (2007). Gender inequality and Development in Nigeria: a Review on Antithesis. South-South Journal of Culture and Development. Forthcoming.

Okafor, E.E. (2005). Corruption and Its Socio-Economic Implications in Nigeria. Nigerian Journal of Clinical and Counselling Psychology, Vol. 11(1): 1-19.

Todaro, M. (1976). Migration and economic development. A review of theory, evidence, methodology and research priorities. Mimeograph, University of Nairobi, Kenya.

United Nations. (1980). Patterns of urban and rural population growth, New York; United Nations Department of International and Social Affairs.

USAID. Urban Profile; 'Nigeria' making cities work. [Online] available: http//www.makingcitieswork.org/files/pdf/Africa/Nigeria

Yamauchi, F. and Tanabe G. (2003). Non-market networks among migrants: evidence from Bangkok, Thailand. International Food Policy Research Institute, Discussion Paper No 16.

Table 1. Logistic Regression for rural-urban migration and other variables

\begin{tabular}{llll}
\hline Variables & Coeff. & Exp $\boldsymbol{\beta}$ & Sig. \\
\hline Education & $1.6014^{*}$ & 0.1766 & 0.01 \\
Unemployment & $8.1744^{* *}$ & 2.9612 & 0.05 \\
Health & 0.3835 & 7.1825 & 0.05 \\
Boredom in Agric. & 4.3015 & 3.4706 & 0.01 \\
Inadequate social amenities & $10.5852^{*}$ & 0.4645 & 0.01 \\
Family reasons & 0.1687 & 0.1252 & 0.01 \\
\hline
\end{tabular}

Source: field survey, 2008

** Significant at $5 \% \quad *$ Significant at $10 \%$ 